\title{
NORFACE
}

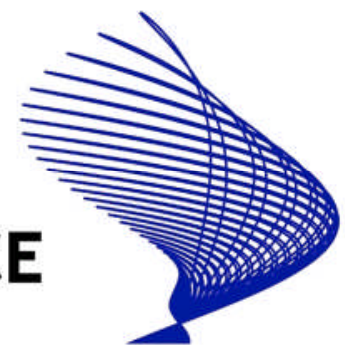

\section{Young immigrant children and their educational attainment}

Asako Ohinata and Jan C. van Ours 


\title{
Young immigrant children and their educational attainment
}

\author{
Asako Ohinata* and Jan C. van Ours ${ }^{\dagger}$
}

August 24, 2012

\begin{abstract}
We analyze the determinants of reading literacy, mathematical skills and science skills of young immigrant children in the Netherlands. We find that these are affected by age at immigration and whether or not one of the parents is native Dutch.
\end{abstract}

JEL classification: I21, J15

Keywords: Immigrant children; Educational attainment

This paper is an extended version of Ohinata and Van Ours (2012)

\footnotetext{
*Department of Economics and CentER, Tilburg University, The Netherlands; email: a.ohinata@uvt.nl

${ }^{\dagger}$ Department of Economics, CentER, Tilburg University, The Netherlands; Department of Economics, University of Melbourne, Parkville, Australia; CESifo, CEPR and IZA; Corresponding author; mailing address: Tilburg University, P.O. Box 90153, 5000 LE Tilburg, The Netherlands; phone: +31-13-4662880; fax: +31-13-4663042; email: vanours@uvt.nl

The authors gratefully acknowledge financial support from the NORFACE research program on Migration in Europe - Social, Economic, Cultural and Policy Dynamics.
} 


\section{Introduction}

In the past decades, the immigrant population has become a substantial part of the society in many European countries. Therefore, more research is conducted focusing on immigrant children particularly on their educational attainment. In many studies, there is a distinction between first-generation immigrants who were born outside the host country with at least one parent also born abroad, and second-generation immigrants who were born in the immigrant country with at least one of the parents born outside the immigrant country. A stylized finding is that in terms of educational attainment, second-generation immigrant children are not very different from native children whereas first-generation immigrant children are performing worse.

The educational attainment of immigrant children in the European context has been investigated in a number of recent studies. For example, Colding et al. (2009) study the gap in high school completion between immigrant children and native Danish children and find that family characteristics and age at immigration are important determinants of the gaps. Bratsberg et al. (2010) do a similar analysis for Norway. Although the gap between immigrant children and native Norwegian children decreased over the past decades, the first-generation immigrant children are especially more likely to leave high school early with this effect being stronger the later the age at immigration. Dustmann et al. (2012) compare the educational gap between second-generation immigrant children and native children aged 15, across several OECD countries. Parental characteristics are an important determinant with a foreign language spoken at home being the single most important factor associated with the educational gap.

There are also a couple on non-European studies. Cortes (2006) analyses educational performance of children in San Diego and Miami finding that the gap in test scores between first-generation and second-generation immigrant children decreases the longer first-generation immigrant children reside in the United States. Sweetman (2010) uses TIMSS data and finds that immigrant scores are on average below those of the domestic born in Canada and the United States, but immigrants in Australia usually have 
scores comparable to those of the domestic born. He also finds that years in the host country have almost no impact on test scores beyond the first year of arrival. Finally, Corak (2011) analyses high-school dropout rates of a cohort of immigrants who arrived in Canada as children. He finds that the chances of being a high-school dropout do not vary according to age at arrival up to age 9 . Children arriving after that age are more likely to not graduate from high school.

In the Netherlands, Van Ours and Veenman (2003, 2006) study the educational gap between the native Dutch and immigrant students, who are aged between 15 and 29. Van Ours and Veenman (2003) find the evidence that the gap in educational attainment between the two groups is smaller for the second-generation immigrants than the first-generation immigrants. Van Ours and Veenman (2006), on the other hand, investigate the effect of age at immigration and present evidence that educational attainment of second-generation immigrants indeed depends on the age at immigration, although the age threshold depends on gender and country of origin. Van Ours and Veenman (2010) explore the effect of interethnic marriages on the educational attainment of Moluccan immigrant children and find that children born from mixed ethnic parents do better than those born from homogeneous ethnic parents. Finally, Schnepf (2007) conducts a cross-country analysis and studies differences in maths and reading test scores between the native and immigrant children in each country. Using similar data as we do she finds that immigrant children in the Netherlands score less than the native children, although only 2 out of 18 estimates suggest statistically significant differences in the test scores between the two groups of students.

In the current paper, we investigate the differences in test scores, between immigrant children in the Netherlands and native Dutch children conditional on personal and family characteristics and classroom environment. Similarly to the existing literature, this paper also highlights the differential educational achievements by first and second-generation immigrants. Moreover, for the first-generation immigrants, we study whether the age at immigration influences the academic achievements.

In contrast to the majority of previous literature that exclusively study the educational attainment of students in junior high school and above, our 
paper uses information on the test scores of children aged 9 and 10. This allows us to study if the educational gap also exists early on in life. Unlike most of the previous studies that measure educational attainment in terms of completed education, our data allow us to make a distinction between language, science and math test scores. The outcomes of all three subjects are studied, since differential levels of linguistic requirements across these subjects may lead us to observe varying degrees of gaps in test scores among students. Moreover, we explore in detail the importance of mixed/homogeneous ethnic marriages and its differential impacts by children's age at immigration.

\section{Data}

Our empirical analysis is based on information on the educational attainment of children in the Netherlands. The datasets employed are the 2006 Progress in International Reading Literacy Study (PIRLS) and the 2007 Trends in International Mathematics and Science Study (TIMSS). These datasets share similar characteristics, since both surveys were designed and conducted by the International Association for the Evaluation of Educational Achievement (IEA). PIRLS assesses the reading abilities while TIMSS collects information on the mathematics and science abilities. The samples of students in both surveys were selected using a two-stage sampling design. In the first stage, schools were selected using a probability-proportional-tosize sampling scheme ; in the second stage, classes were randomly sampled from each of the selected schools. ${ }^{1}$

Similar sets of covariates are available from both PIRLS and TIMSS. For example, at the individual student level, PIRLS and TIMSS hold information on age and gender of students and the number of books at home. However, the highest educational qualifications of parents are only available in PIRLS. As a result, we also use the information on the number of books at home as a proxy for the parental educational background. The science and math results are from TIMSS-2007 and based on 1475 observations from 113 classrooms. There are 111 first-generation immigrants, 225 second-generation immigrants and 146 of these immigrant children are from

\footnotetext{
${ }^{1}$ See our companion paper, Ohinata and Van Ours (2011) in which we investigate the presence of negative spillover effects from immigrant children to native Dutch children.
} 
mixed marriages. The reading scores are from PIRLS-2006 and based on 1591 observations from 116 classrooms. There are 25 first-generation immigrants, 185 second-generation immigrants and 141 immigrant children from mixed marriages.

Table 1 provides summary statistics for the various groups of children, distinguished by immigrant status. Panel $a$ shows that there are big differences in average science test scores and math test scores between the three groups of children. Native children have test scores that are on average 25 to 30 points higher than second-generation immigrant children who in their turn have scores that are on average 20 to 25 points higher than those of first-generation immigrant children. In the TIMSS data, about half the second-generation immigrant children have parents of which one is native. For first-generation immigrants this is about one-third. Among the first-generation immigrant children the share of girls is much lower than among native children and second-generation immigrant children. The average number of books which we use as an indicator for parental educational attainment is higher in homes of native Dutch children and lowest in homes of first-generation immigrant children. Whereas 20 percent of the firstgeneration children have 10 books or less at home, this is the case for only 4 percent of the native children.

Panel $b$ of Table 1 shows that the average reading test scores do not differ a lot between native children and second-generation immigrant children. The difference is 5 points, whereas the difference between secondgeneration immigrant children and first-generation immigrant children is 25 points. In the PIRLS sample about three-quarter of the second generation immigrant children are from a mixed marriage, which is about one-third for first-generation immigrant children. The percentage of girls is very high among first-generation immigrant children, but this may be coincidental and related to the small sample size. The distribution of the number of books at home is not very different from the children in the TIMSS sample. The PIRLS data also contain information on parental educational attainment. The educational attainment of the parents is higher for native Dutch children than for second-generation immigrants. Somewhat surprisingly the educational attainment of first-generation immigrants is rather high. Again, 
this may have to do with the small sample size for the first-generation immigrants.

\section{Stylized facts}

Figure 1 provides the distributions of test scores of the different groups of children. The top graph shows the distribution of the science test scores. There is a clear ordering with native children having the highest test scores and first-generation immigrants having the lowest test scores. However, at the top end of the distribution the difference between native children and second-generation immigrant children is not so big. The distribution of science test scores for second-generation immigrant children has a fat left tail indicating that there are quite a few children who have a low score. First-generation immigrant children have a long left tail of the distribution of science test scores. Although the distributions of the math test scores shown in the middle graph are similar there are also some differences. The distribution for the native children has two peaks and the high-end distribution for the second-generation immigrant children is not so close to the distribution for the native children as was the case for the distribution of the science test scores. The bottom graph of Figure 1 shows the distributions of the reading test scores indicating that there are only small differences between native children and second-generation children. The distribution for the first-generation immigrant children is to the left of the other two groups but note that this is based on only a few observations.

Figure 2 presents the distributions of the test scores for second-generation immigrant children distinguished by whether or not they have two immigrant parents. From the top graph it is clear that children from mixed marriages perform much better in terms of their science test scores than children with two immigrant parents do. Whereas for children from mixed marriages there is a lot of probability mass at the high end of the distribution, for children with two immigrant parents this is the case at the low end of the distribution. The middle graph shows that for math test scores there are also clear differences although they are not as big as for the science scores. Finally, the bottom graph of Figure 2 shows that for reading test scores the differences 
are not that big either.

Figure 3 is similar to Figure 2, but for first-generation immigrants. We did not include the distributions of the reading test scores because the number of observation for first-generation immigrant children in the PIRLS dataset is too small. Both for the science test scores as well as the math test scores, there are differences between first-generation immigrants from mixed marriages and first-generation immigrant children with two immigrant parents but especially for the math scores the differences are not that big.

\section{Set-up of the analysis}

In our empirical analysis, we estimate the parameters of the following equation:

$$
y_{i c}=\beta x_{i}+\epsilon_{i c}
$$

where $y_{i c}$ denotes the test score for the $i^{\text {th }}$ student in $c^{\text {th }}$ classroom, $x_{i}$ captures the students' individual and family characteristics. Furthermore, the error term, $\epsilon_{i c}=\alpha_{c}+u_{i c}$, is composed of two terms: $\alpha_{c}$ reflects the classroom fixed effects and $u_{i c}$ is the random error term. Our data allow us to investigate the effects of the following individual and family characteristics: whether a child is a first-generation or second-generation immigrant, whether the parents of the child form a mixed couple (i.e. mother and father are native and immigrant), the gender and age of the child and the number of books at home. The number of books at home is specified in discrete intervals (up to 10, 11 to 25, 26 to 100, 101 to 200 and more than 200) for which we use dummy variables. Our data also allow us to include classroom fixed effects in our estimates.

\section{Parameter estimates}

The parameter estimates of equation (1) are presented in Table 2. The first column shows the parameter estimates for the science scores. Secondgeneration immigrant children have a significantly lower science test score 
compared to native children, while first-generation immigrants children have an even lower science test score. Having parents from a mixed marriage lead to a positive and significant effect on the science score of their children. ${ }^{2}$ The size of this effect is about the same in magnitude - but opposite in sign as the second-generation dummy. This implies that second-generation immigrant children from a mixed marriage have about the same educational attainment as native children. Girls have a significantly lower science score than boys while age has no effect. The second column of Table 2 shows the effects of introducing classroom fixed effects. These represent a variety of potential effects such as geographical location, school characteristics, educational resources but also unobserved heterogeneity at the level of families and individuals. Controlling for the classroom unobserved characteristics uniformly reduces the effects of being an immigrant child, in absolute sense, although the general pattern is unaffected. The third and fourth columns show that this general pattern is also present for the math scores. The fifth column of Table 2 shows that for the reading scores there is only one significant parameter. First-generation immigrants have a significantly lower reading score than native children, while second-generation immigrant children do not suffer significant disadvantages compared to the native children. Introducing classroom fixed effects or parental education dummies as additional explanatory variables does not change these results.

In Table 3, we explore whether age at immigration has an effect on the educational attainment of the immigrant children. Age at immigration information is only available in TIMSS and, therefore, this analysis is only possible for the science and math scores and not for the reading scores. The first column shows that the negative effect of being a first-generation immigrant on the science score increases in absolute terms if the age at immigration increases, but the effect is not strong. The second and third columns of Table 3 show parameter estimates if we interact the immigrant dummies with parental marriage. There seems to be no significant effect on the science score for immigrant children born from interethnic parents. ${ }^{3}$ For

\footnotetext{
${ }^{2}$ We also investigated whether it mattered if the father or the mother was native, but we found no evidence for this. The finding of Van Ours and Veenman (2010), which indicates that a mixed marriage is only better for the educational performance of Moluccan children if the mother is native, is probably specific to the Moluccan immigrant group.

${ }^{3}$ The significant negative effect of the first generation dummy for 1-5 years age at
} 
first-generation immigrant children with two immigrant parents, there is a clear relationship between science score and age at immigration. Children who entered at age 5 or older have a much lower science test score than children who entered as a baby, who have about the same science test score as second-generation immigrant children. The fourth to sixth columns of Table 3 show similar parameter estimates for the math test scores.

\section{Conclusions}

We analyze the determinants of the educational attainment of young children in the Netherlands. Our analysis uses data from various sources, which allow us to characterize educational attainment in terms of reading literacy, mathematical skills and science skills. We find that immigrant children aged 9 and 10 perform worse in terms of science and maths test scores compared to native Dutch children whereas almost no significant differences are found when we look at the effects on reading test scores. The negative performance is observed particularly among the first-generation immigrant children. Only if their parents have a mixed marriage (i.e. marriages in which either the mother or father is native Dutch) does this worse performance

disappear. Results from further analysis on science and maths test scores suggest that age at immigration is important particularly for immigrant children born from homogeneous ethnicity marriages. More specifically, negative educational achievements are observed the later these children arrived in the Netherlands. The lower educational achievement among immigrant children may be caused by the linguistic barriers faced by them. However, this is likely to be only part of the story. Our results suggest that secondgeneration immigrants have no lower language scores compared to native Dutch children irrespective of the origin of their parents. Another potential explanation for the finding is that families with two immigrant parents are on average less oriented to schooling performance or less equipped to support their children. For example, if both parents are immigrants, they may find it more difficult to integrate and acquire relevant educational information during the parent group meetings held at school.

immigration may have to do with the small sample size. 


\section{References}

- Bratsberg, B., Raaum, O., Roed, K., 2011. Educating children of immigrants: closing the gap in Norwegian schools. IZA Discussion Paper, 6138, Bonn.

- Colding, B., Husted, L., Hummelgaard, H., 2009. Educational progression of second-generation immigrants and immigrant children. Economics of Education Review, 28, 434-443.

- Corak, M., 2011. Age at immigration and the educational outcomes of children. IZA Discussion Paper No. 6072, Bonn.

- Cortes, K.E., 2006. The effects of age at arrival and enclave schools on the academic performance of immigrant children. Economics of Education Review, 25, 121-132.

- Dustmann, C., Frattini, T., Lanzara,G., 2012. Educational achievement of second generation immigrants: an international comparison. Economic Policy, $69,143-185$.

- Ohinata, A., Van Ours, J.C., 2011. How immigrant children affect the academic achievement of native Dutch children. CentER Discussion Paper, 11136, Tilburg University.

- Ohinata, A., Van Ours, J.C., 2012, Young immigrant children and their educational attainment. Economics Letters, 3, 288-290.

- Schnepf, S.V., 2007. Immigrants' educational disadvantage: an examination across ten countries and three surveys. Journal of Population Economics, 20, $527-545$.

- Sweetman, A., 2010. Immigrant children in elementary school: an international perspective. in: McDonaldd, T., Ruddick, E., Sweetman, A., Worswick, C. (eds.), Canadian Immigration: Economic Evidence for a Dynamic Policy Environment. Montral and Kingston: Queen's Policy Studies Series, McGill-Queen's University Press.

- Van Ours, J.C., Veenman, J., 2003. The educational attainment of secondgeneration immigrants in the Netherlands. Journal of Population Economics, 16, 739-753.

- Van Ours, J.C., Veenman, J., 2006. Age at immigration and educational attainment of young immigrants. Economics Letters, 90, 310-316.

- Van Ours, J.C., Veenman, J., 2010. How interethnic marriages affect the educational attainment of children: evidence from a natural experiment. Labour Economics, 17, 111-117. 
Table 1: Means of variables

\begin{tabular}{|c|c|c|c|c|c|c|}
\hline & Natives & $\begin{array}{c}\text { Second } \\
\text { generation }\end{array}$ & $\begin{array}{c}\text { First } \\
\text { generation }\end{array}$ & Total & Min & $\operatorname{Max}$ \\
\hline \multicolumn{7}{|l|}{ a. TIMSS } \\
\hline Science test score & 540 & 509 & 485 & 531 & 297 & 709 \\
\hline Math test score & 549 & 524 & 503 & 542 & 300 & 710 \\
\hline Parents mixed marriage & 0.00 & 0.49 & 0.32 & 0.10 & 0 & 1 \\
\hline Female & 0.50 & 0.53 & 0.43 & 0.50 & 0 & 1 \\
\hline Age & 9.65 & 9.61 & 9.72 & 9.65 & 9 & 10 \\
\hline \multicolumn{7}{|l|}{ Books at home } \\
\hline 10 or less & 0.04 & 0.15 & 0.20 & 0.07 & & \\
\hline $11-25$ & 0.44 & 0.28 & 0.29 & 0.27 & 0 & 1 \\
\hline $26-100$ & 0.49 & 0.40 & 0.33 & 0.42 & 0 & 1 \\
\hline $101-200$ & 0.36 & 0.11 & 0.11 & 0.15 & 0 & 1 \\
\hline More than 200 & $\underline{0.31}$ & $\underline{0.07}$ & $\underline{0.07}$ & $\underline{0.10}$ & 0 & 1 \\
\hline Total & $\overline{1.00}$ & $\overline{1.00}$ & $\overline{1.00}$ & $\overline{1.00}$ & & \\
\hline Observations & 1139 & 225 & 111 & 1475 & & \\
\hline \multicolumn{7}{|l|}{ b. PIRLS } \\
\hline Reading test score & 562 & 557 & 532 & 561 & 376 & 684 \\
\hline Parents mixed marriage & 0.00 & 0.71 & 0.36 & 0.09 & 0 & 1 \\
\hline Female & 0.51 & 0.55 & 0.64 & 0.52 & 0 & 1 \\
\hline Age & 9.64 & 9.64 & 9.56 & 9.64 & 9 & 10 \\
\hline \multicolumn{7}{|l|}{ Books at home } \\
\hline 10 or less & 0.11 & 0.13 & 0.24 & 0.11 & & \\
\hline $11-25$ & 0.14 & 0.17 & 0.24 & 0.15 & 0 & 1 \\
\hline $26-100$ & 0.30 & 0.30 & 0.12 & 0.30 & 0 & 1 \\
\hline $101-200$ & 0.18 & 0.16 & 0.16 & 0.18 & 0 & 1 \\
\hline More than 200 & $\underline{0.26}$ & $\underline{0.24}$ & $\underline{0.24}$ & $\underline{0.26}$ & 0 & 1 \\
\hline Total & $\overline{1.00}$ & $\overline{1.00}$ & $\overline{1.00}$ & $\overline{1.00}$ & & \\
\hline \multicolumn{7}{|l|}{ Education parents } \\
\hline Higher & 0.43 & 0.38 & 0.56 & 0.42 & 0 & 1 \\
\hline Post-secondary & 0.03 & 0.03 & 0.04 & 0.03 & 0 & 1 \\
\hline Upper-secondary & 0.35 & 0.32 & 0.20 & 0.34 & 0 & 1 \\
\hline Lower & $\underline{0.19}$ & $\underline{0.27}$ & $\underline{0.20}$ & $\underline{0.21}$ & & \\
\hline Total & $\overline{1.00}$ & $\overline{1.00}$ & $\overline{1.00}$ & $\overline{1.00}$ & & \\
\hline Observations & 1381 & 185 & 25 & 1591 & & \\
\hline
\end{tabular}




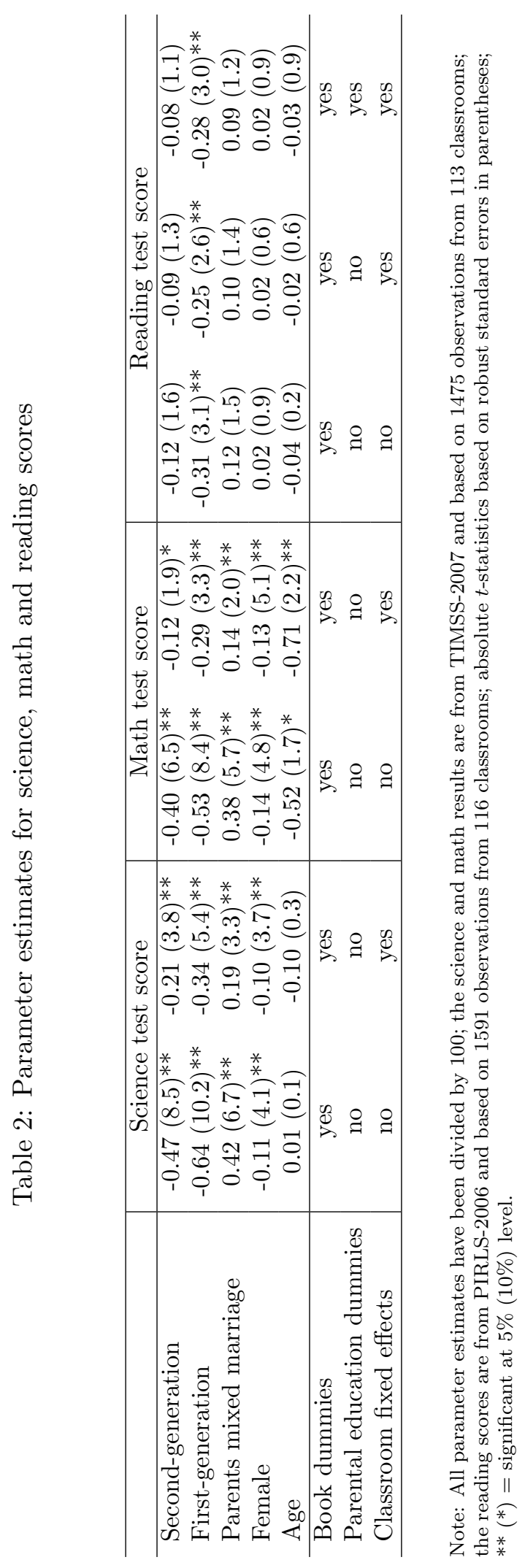




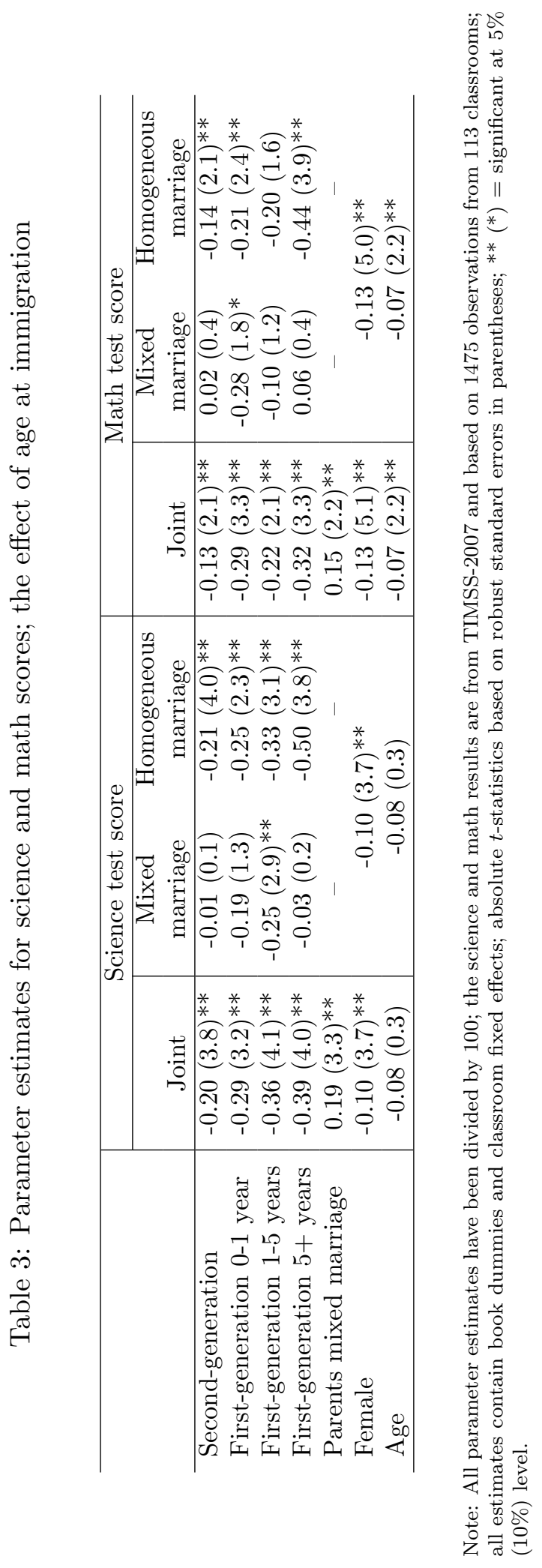



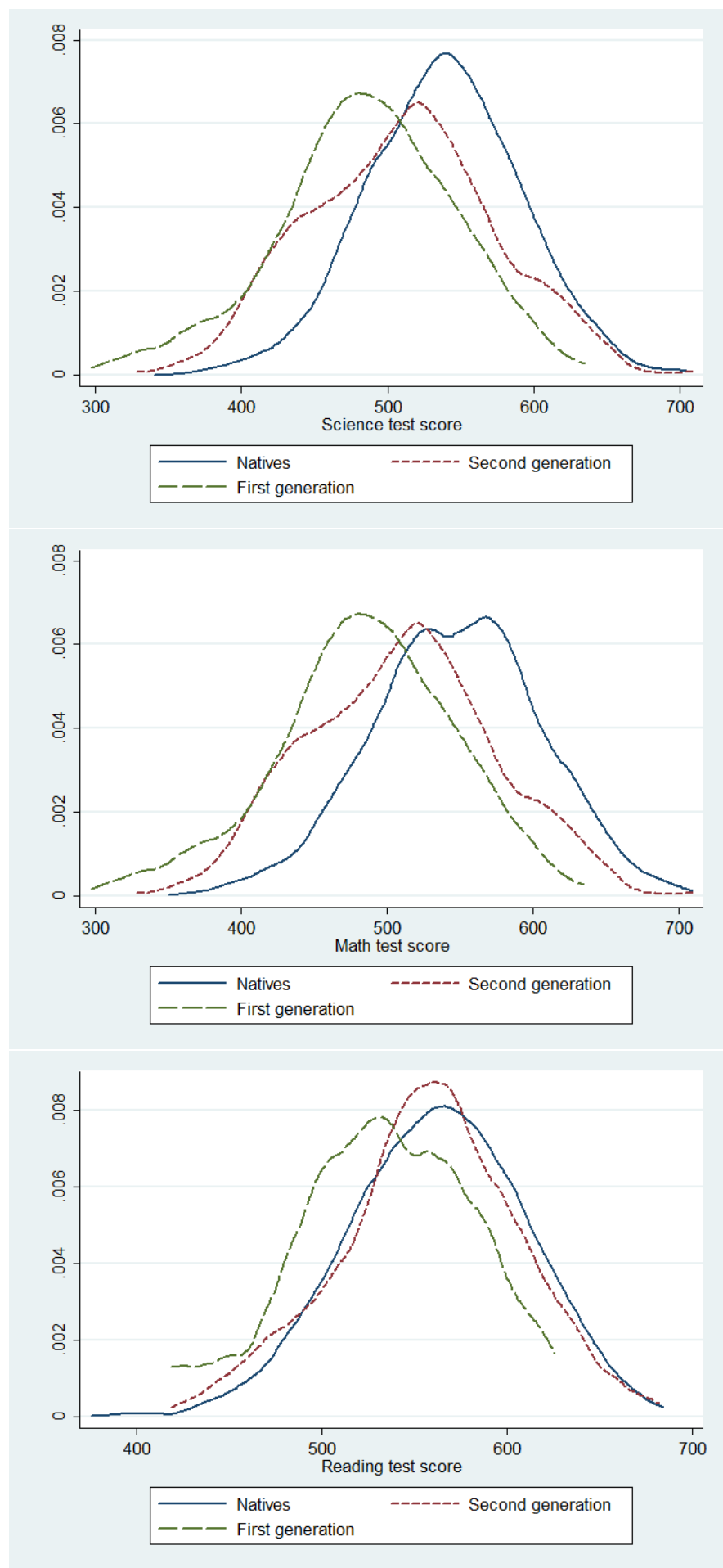

Figure 1: Kernel densities; test scores children 9-10 by immigrant type; science (top), math (middle), reading (bottom) 

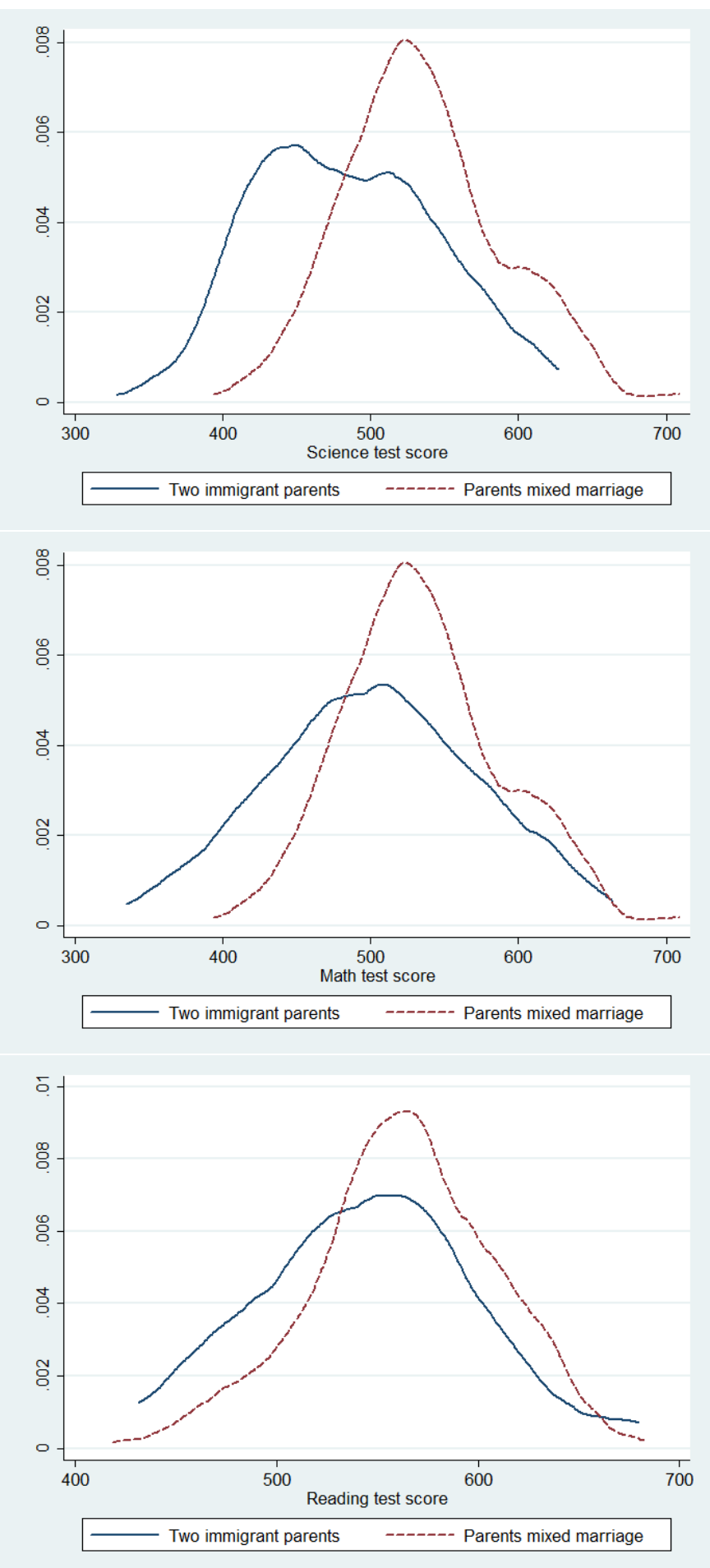

Figure 2: Kernel densities; test scores second-generation immigrant children 9-10 by type of marriage parents; science (top), math (middle), reading (bottom) 

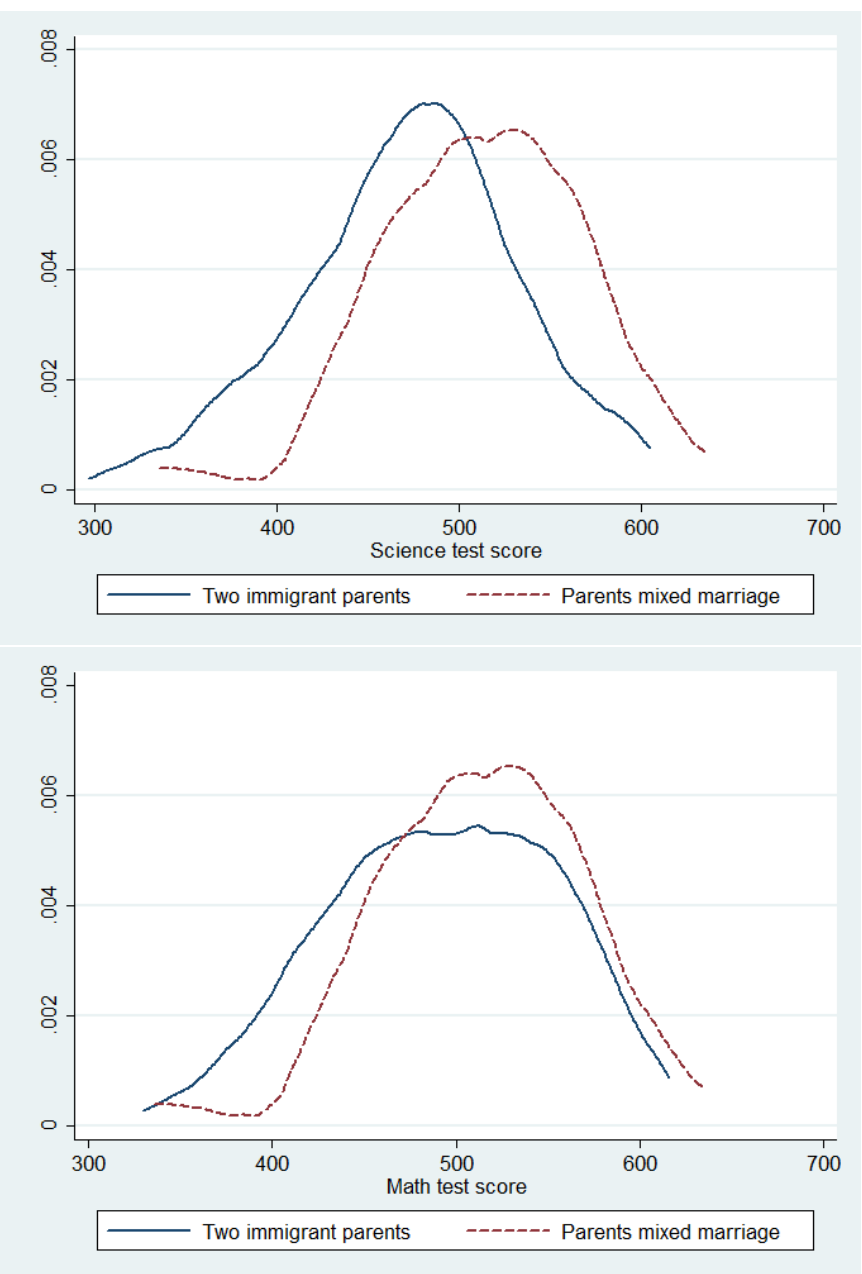

Figure 3: Kernel densities; test scores first-generation immigrant children 9-10 by type of marriage parents; science (top), math (bottom) 